\title{
PROPTOSIS AND DIPLOPIA AS CONSEQUENCES IN TRAUMA OF CRANIOFACIAL JUNCTION
}

\author{
Srbislav Pajic ${ }^{1}$, Tanja Boljevic ${ }^{2}$, Svetlana Antic ${ }^{3}$, Milutin Mrvaljevic ${ }^{1}$, Milena Cojic $c^{4}$, Jovan Janic $^{5}$, Zoran Pešic ${ }^{5,6}$ \\ ${ }^{I}$ The Centre for Medical Emergencies and Neurotrauma Emergency Center, KSC, Belgrade, Serbia \\ ${ }^{2}$ Clinic of Otorhinolaryngology and Maxillofacial Surgery, Clinical Center of Montenegro, Podgorica, Montenegro \\ ${ }^{3}$ Faculty of Dentistry University of Belgrade, Center for Radiological Diagnostics, Belgrade, Serbia \\ ${ }^{4}$ Health Center Podgorica, School of Medicine, Podgorica, Montenegro \\ ${ }^{5}$ Faculty of Medicine, University of Niš, Serbia \\ ${ }^{6}$ Clinic of Dentistry, Department of Maxillofacial Surgery, Niš, Serbia
}

\begin{abstract}
In the trauma of craniofacial junction, frontal sinus wall fractures take up 5-15\% of all facial bone fractures. The most common mechanism of their occurrence comes as a result of the action of high-energy impact force on the frontal area. Treatment of the injuries in frontal-orbital-ethmoidal regions largely depends on the responsible experts (otolaryngologist, maxillofacial surgeon or neurosurgeon) in all cases, because of the implementation of diverse surgical technics in order to achieve the best possible outcome for the patient. Bearing in mind the complex anatomical features of this region, it is clear that these procedures are often accompanied by series of possible complications, all of which are certainly neurosurgical. These can be expressed as early or late complications, and could be characterized by diverse clinical manifestations. Mucocele is formed, either due to partial obstruction of the sinus mucosa or due to the obstruction of the frontal sinus. The long term existence of mucocele and its progressive growth will result in strong pressure on the adjacent bones, and lead to their destruction followed by the process-propagation into surrounding tissues and spaces. In the further development if a bacterial contamination is detected, it will lead to the purulent inflammatory process and clinical picture of mucopyocele. In most clinical cases with complications proptosis and diplopia are dominant ophthalmic manifestations. In this paper we will present our experience in the treatment of proptosis and diplopia, as well as the ways of diagnostic evaluation in order to achieve timely diagnosis and assure swift healing of patients.
\end{abstract}

Key words: diplopia, proptosis, frontal sinus, craniofacial trauma.

\section{Introduction}

Long persisting chronic pain syndrome can be an indicator of long-term complications, such as mucopyocele, osteomyelitis or mucocele that occur as a complication of trauma, mainly due to partial mucosal lining retention. Obstruction of sinus cavity can occur as a result of congenital anomalies, infection, trauma, allergies, and tumors or as a result of surgical procedures in the nasal cavity [1]. Continued secretion of mucus and its accumulation leads to formation of mucocele that grows over time causing atrophy or erosion of the bones of sinuses and surrounding bone structure, further extending by the path of least resistance [2,3]. Mucoceles are considered as tumors and destructive lesions [4]. The most common ways of spreading include propagation in

*Correspondence to: Srbislav Pajić, M.D.

Center for Medical Emergencies and Neurotrauma Emergency Center KSC, 2 Pasterova St, 11000 Belgrade, Serbia

Phone: +381649030226

E-mail: nevus-ng@hotmail.com

Received May $17^{\text {th }}, 2017$, accepted for publication June $6^{\text {th }}, 2017$ the orbital cavity, surrounding sinus cavities, or nasal cavum with induration of surrounding soft tissue. In this manner, formed soft tissue cystic formation is covered with pseudostratified epithelium and its content is very often clear mucus, yellowish, sticky liquid, when we are talking about simple mucocele, or pus yellowish, thick and opalescent liquid, when we have secondary infections and then we are referring to an entity known as mucopyocele. Size, propagation time, duration and possible bacterial contamination of mucocele affect the formation of ophthalmic disorders [5]. Mucocele, in its development process, will grow in size and thus, provoke the thinning of the surrounding bone structure and eventually cause bone absorption. In the beginning, mucocele of the frontal sinus does not give any symptoms. Their growth and spreading through the bottom wall of the sinus results in protrusions, while a growth towards orbit causes exophthalmos (protrusion of the eyeball) and lateral position of the eyeball. Mobility of the eye balls is preserved. In mucocele of ethmoidal sinus tumefaction occurs in the inner corner of the eye and with long term dacryocystitis upward lateral positioning of ocular bulbus 
occurs. Also, in case of rare localization of mucocele in sphenoidal sinus we witness the appearance of the optic nerve atrophy, complications involving the pituitary gland function and exophthalmos. Furthermore, it may lead to destruction of the bulbus or to the suppression of peri-bulbar tissue, which is followed by occurrence of proptosis, diplopia or disturbance in the field of vision, or in worst case scenario could even lead to blindness. Long-persisting unilateral proptosis is a common consequence of injuries of craniofacial junction [6]. Craniofacial trauma is manifested as multisystem injuries in $20-50 \%$ of cases [7].

Risk factors that can allow the formation of posttraumatic complications largely depend on the method of treatment of these injuries in the primary act, the presence or absence of naso-frontal channel, and its level of obstruction [8,9]. Risk factors that are also mentioned as possible causes, and which have been mentioned in literature, refer to different technics in preforming plastic and reconstruction surgery of the walls of the sinuses and sinus cavity after trauma [10,11]. The importance of the presence or absence of naso-frontal channel and its condition in the trauma and after surgery is especially emphasized in prognostics. Rodriguez et al. [12] suggest a certain algorithm procedures in the treatment of the injury sinus, which is backed up by a comprehensive series of patients, and is based on the fact that the decision about treatment should derive from a variety of factors to consider: the type of fracture, the extent of damage to the back wall of sinus and naso-frontal channel, the neurological status of the patient and the presence of associated trauma and existence of nasal liquorrhea [13-16].

\section{Case Reports}

\section{Case No.1}

Patient (M.G.) is a white, 48 year-old male (Figure 1), with present proptosis, diplopia expressed in his right eye, experiencing persistent dull pain in orbit and head and the occasional outburst in the peripheral field of vision (tubular form) in the form of blurred and sometimes distorted vision of objects. The mobility of his right eye is limited and difficult, and when asked to look in all directions a distinct diplopia is noted. The anamnesis suggests that he had an injury in traffic 22 years ago as a driver (Figure 3 shows the presence of non-rehabilitated fracture in the frontal sinuses), and except for bleeding from both nostrils and bilateral infra orbital hematoma, he reports having no other problems. Throughout the past period of time he had occasional headaches that have reacted to painkillers and uncontrollable flow of tears over the edge of the lower eyelid. He stated that the symptoms intensified during last month thus he revisited his physician. After preforming diagnostics in the form of echo sonographic test of orbital cavity (cystic formation was detected in retrobulbar and posterior superior position), computerized tomography (CT) with 3D reconstruction (Figures 1, 2, 4) showed formations coming from the right frontal sinus and extending above the roof of the right orbit destroying on its way the upper bone dome, descending in retrobulbar direction, pushing out the contents of the orbit and communicating with muscular structures of the eye. Its mass suppressed the existing anatomical structures of the right orbit, leading to proptosis). On the basis of the above medical information, clinical, ultrasound and CT diagnostics, we can make a conclusion that it is a case of mucocele, which we verified later, both intraoperatively and by histopathology. The patient underwent surgery, where mucocele was identified. is the mucocele was removed in its entirety, followed by a reconstruction of the roof of orbit and the wall of the frontal sinus through designed bone graft from calvaria (skull cap). Figure 2 shows the removed mucocele, with horizontal diameter 38.4 x $32.5 \mathrm{~mm}$ and vertical diameter 37.5 x $46.7 \mathrm{~mm}$. Postoperatively, after six months, there were no signs of proptosis and diplopia, while the patient reported absence of all symptoms.

\section{Case No 2}

Patient (R.M.) is a white 22. year-old female, with a history of a fall from a height which occurred five years previously, with reported trauma in the frontal sinus, with clinical picture of persistent headache for 6 months, stating that she had no previous surgery. Clinical examination shows mild proptosis of left upper eyelid with ocular bulbs movement slightly laterally and inferiorly. MRI showed tumor in frontal- ethmoid region that suggested the presence of mucocele (Fig. 5) in the left frontal sinus with significant penetration into orbit and much less present in the right side. Intraoperatively, we found mucocele in the left orbit along with destruction of part of a roof of orbit and compression to medial rectus muscle and ocular bulbus. Most of the surgery was done trough bicoronal approach arched section. Upon accessing and identifying changes, they were removed and sent to HP verification. Detected defects on the roof of the orbits were reconstructed with bone chip taken from external tabula, and then sealed with the tissue adhesive. Postoperative course was regular, clinical and local controls showed satisfactory finding. The aesthetic results were satisfactory and no complications related to the procedure developed, such as uncontrolled bleeding from sinus infections, damage to the posterior wall of the sinuses and brain.

\section{Discussion}

The anamnestic data gathered from the patient about gradually appearing unilateral proptosis presented us with clinical and diagnostic challenge, and lead us to doubt the persistence of mucocele [17-19], in addition to revising the possibility of the existence of diseases of organs of the eye, the retrobulbar orbital tumors, inflammatory pseudo tumor, sinus tumor and non- 
metastatic lesions. Moreover, clinical reports commonly show patients presented with mucocele of frontal sinus, manifesting the eye motility disorders, lowered upper eyelid, decreased rima oculi, diplopia, unilateral proptosis, epiphora, dull periocular pain and sometimes the occasional outburst in the field of vision. In this case, pupils were equal and reactive. All patients had medical reports that confirm traumatic injuries in the frontal area with mild swelling of the area. Furthermore, if amansetic data report presence of an earlier trauma in craniofacial region we are more likely to conclude that posttraumatic mucocele is present. Progressive, unilateral painless proptosis, with gradual onset, should raise suspicion of a mucocele of sinus, mainly in frontal (Figure 1, Figure 2, Figure 4) or ethmoidal sinus, as these are the most common sites for this type of affliction [20-24]. Doubt is amplified even more if there are accompanying diplopia, present pain in periorbital area or at the forehead, and epiphora, as these are often accompanying symptoms of mucocele [5].

Size and expansion rate of mucocele are directly connected with multitude and gravity of accompanying symptoms that follow this disease.

The level of presence of the ptosis can vary in patients who experience cold or inflammation of the sinuses. The existence of mucocele at times can be associated with chronic sinus inflammation, nasal obstruction or traumatic consequences [25-27]. Patient can exhibit blurred or impaired vision or even a complete loss of vision, as a sign of evident proptosis. The reasons for the loss of vision can be diverse. It can be due to the direct compression of optical nerve in orbital area, and vascular or inflammatory process which pertains to the optical nerve, refractive error in the eye, keratopathy or secondary glaucoma. Ophthalmological manifestations which are described by patients are often evidence of persisting mucocele in craniofacial junction, deriving from frontal sinus. Usually, patients are noting the swelling formation under the eye, followed by occurrence of diplopia. Moreover, all of the above can also include mechanical pressure applied onto the optical nerve which will cause impairment of vision. Another well noted complication of mucocele is erosion of the frontal bone structure of the wall of sinus which leads to protrusion of the mass beneath the periostea of the frontal bone. Erosion of the back wall of the frontal sinus may result in epidural abscess, meningitis, subdural empyema and brain abscess. Rarely, the cranial nerve can be affected. RTG presentation of mucocele is manifested by bone dilution and expansion of the walls of sinus by the formation of mucocele, with the presence of bone erosion. RTG description of mucocele is characterized by homogenous hyperdense formation which fills up the lumen of frontal sinus. Standard RTG procedures will show the presence of the lesion, while CT will give us better insight in its size and its relation to the surrounding structures, such as bone and mucocele contact, and intracranial and orbital propagation which in final instance recommends the surgical extent of the treatment. In addition, CT scans will provide us with information about liquid presence inside mucocele and its density. It will also allow us the insight in the volume of the lesion and its propagation towards surrounding structures. MRI on the other hand can detect mucocele but may lead us to wrong conclusion by presenting condensed mucus in sinus as air filled cavity $[16,22]$.

In patient No.1, computed tomography (CT) showed a picture of mucocele with its soft content, where its largest part occupies the front part of the zone of sphenoidal bone and frontal sinus on the right, with osteolytic process in the roof of orbital cavity and pushed eyeball and peri-bulbar tissues downwards and outwards, with all the signs of remodeled anatomy. We notice the old untreated fracture of frontal-nasalethmoidal complex.

In patient No. 2, the diagnosis was made by magnetic resonance imaging (MRI) with the idea to clarify that this is not a malignant process. The disadvantage of MRI is primarily in the inability of these procedures to assess the bone anatomy and relationship of the discovered entity with this structure. In the second case, we have discovered a benign process in the right and left frontalethmoidal aspect.

Due to the inability of MRI to differentiate bone walls separating the orbital cavity from adjacent sinuses, we were not able to assess whether mucocele propagate into orbit or not. However, with suggestive clinical data, which indicate that mucocele originates from the sinus cavities of the frontal sinuses and causes proptosis, CT of the orbit should be the first choice of diagnostic tool to use. MRI plays a role in diagnosis because it can provide information in the study of the orbital cavity and serve as a diagnostic procedure of choice in suspicion of other soft tissue tumors that affect the appearance of proptosis and are not caused by mucocele.

Orbit ultrasonography is a noninvasive procedure that can be a very informative technique in the display of tissue as it helps to determine whether the lesion is cystic or solid.

Differential diagnosis of mucocele includes encephalocele, a cholesterol granuloma, epidermoid cyst, meningioma, chordoma, neurofibroma, para-ganglioma, nasal-angio-fibroma and malignant neoplasms. The diagnosis of mucocele is based on history, clinical examination and radiological findings.

The definitive treatment of mucocele is primarily surgical. The aim of the implementation of surgical treatment is largely dependent on the size, location and extent of mucocele. The main task is to empty the mucocele and allow ventilation of the sinuses and reestablish its adequate drainage, taking into account that there are no functional and cosmetic deformities, and respecting the principles of reconstruction of damaged bone structures that play a role in supporting vital structures. The lining of the cyst has to be removed completely and inspection should establish that the bone is left without impurities from mucosal cysts. We 
approached these mucoceles by external open obliterative procedure, because it seemed to be more cosmetically acceptable and attractive procedure in order to lift the lid of frontal bone by osteoplastic technique [28-30], which is valid for adequate and comprehensive approach. The purpose of the surgery itself should enable us to achieve good surgical outcome.

\section{Conclusion}

The presence of frontal mucocele can occasionally be accompanied by ophthalmologic manifestations such as proptosis and diplopia. Since this is a benign, long developing disease, early recognition of symptoms of its

\section{References}

1. Diaz F, Latchow R, Duvall A J 3rd, Quick C A,Erickson D L. Mucoceles with intracranial and extracranial extensions. J Neurosurg 1978; 48:284-288.

2. Alberti P W, Marshall H F, Black J I. Fronto-ethmoidal mucocele as the cause of unilateral proptosis.Br J Ophthalmol 1968; 52:833-838

3. Sabari R,Singh SP, Reddy N, Post Traumatic Frontal Swelling with Propoptosis and Diplopia. Arch CranOroFac Sc. 2013; 1(1):1-5

4. Abrahamson I A, Baluyot S T, Tew J M, Scioville G. Frontal sinus mucocele. Ann Ophthalmol 1979; 2:173-178.

5. Avery G, Tang R A, Close G C. Ophthalmic manifestations of mucoceles. Ann Ophthalmol 1983; 15:734-737.

6. Kaufman S J. Orbital mucopyoceles. Two cases and a review. Surv Ophthalmol 1981; 25:253-262.

7. Fazakas A. A contribution to the symptomatology of a mucocele in ophthalmology. Ophthalmologica 1953; 25:175-182.

8. Jain SA, Manchio JV, Weinzweig J. Role of the sagittal view of computed tomography in evaluation of the nasofrontal ducts in frontal sinus fractures. J Craniofac Surg 2010; 21(6):1670-1673.

9. Mortada A. Radiography in mucocele of the frontal sinus. Am J Ophthalmol 1967; 64:1162-1167.

10. Iliff C E. Mucoceles in the orbit. Arch Ophthalmol 1973; 89:392-395.

11. Donald PJ, Bernstein L. Compound frontal sinus injuries with intracranial penetration. Laryngoscope 1978; 88(2 Pt 1):225-232.

12. Lee JC, Andrews BT, Abdollahi H, Lambi AG, Pereira CT, Bradley JP. Computed tomography image guidance for more accurate repair of anterior table frontal sinus fractures. J Craniofac Surg 2015; 26(1):e64-e7.

13. Fujitani T, Takahashi T, Asai T. Optic nerve disturbance caused by frontal and frontoethmoida mucopyoceles. Arch Otolaryngol 1984; 110:267-269.

14. Ehrenpreis S J, Biedlingmaier J F. Isolated third nerve palsy associated with frontal sinus mucocele. Neuro-ophthalmol 1995; 15:105-108.

15. Bordley JE, Bosley WR. Mucoceles of the frontal sinus: causes and treatment. Ann Otol Rhinol Laryngol. 1973 Sep-Oct. 82(5):696-702.

16. Gerbino G, Roccia F, Benech A, Caldarelli C. Analysis of 158 frontal sinus fractures: current surgical management and complications. J Craniomaxillofac Surg 2000; 28(3):133-139.

17. Yavuzer R, Sari A, Kelly CP, et al. Management of frontal sinus fractures. Plast Reconstr Surg 2005; 115(6):79e-93e; discussion 94e-95e. presence, and it timely surgical removal is very important for the patients' swift recovery. Adequate evaluation of clinical symptoms and radiological evaluation of the appropriate method of examination are very important for timely establishment of the correct diagnosis, which will, then, result in a high percentage of therapeutic success.

It is up to the surgeon to decide on the choice of optimal treatment in a particular case, and depending on the size and volume of the mucocele, along with factors related to the patient (age, anatomy, spatial propagation, the size changes, etc.), the decision of best surgical technique in order to solve the existing problem will be made.

18. Cormier J, Manoogian S, Bisplinghoff J, Rowson S, Santago A, McNally C. The tolerance of the frontal bone to blunt impact. J Biomech Eng 2011 Feb. 133(2):021004.

19. Yoo A, Eun SC, Baek RM. Transcutaneous reduction of frontal sinus fracture using bony tapper device. J Craniofac Surg 2012; 23(6):1835-1837.

20. Choi M, Li Y, Shapiro SA, Havlik RJ, Flores RL. A 10-year review of frontal sinus fractures: clinical outcomes of conservative management of posterior table fractures. Plast Reconstr Surg 2012; 130(2):399-406.

21. Garg RK, Afifi AM, Gassner J, et al. A novel classification of frontal bone fractures: the prognostic significance of vertical fracture trajectory and skull base extension. J Plast Reconstr Aesthet Surg 2015; 68 (5):645-653.

22. Stanwix MG, Nam AJ, Manson PN, Mirvis S, Rodriguez ED. Critical computed tomographic diagnostic criteria for frontal sinus fractures. J Oral Maxillofac Surg 2010; 68(11):2714-2722.

23. Kim YJ, Kim HR, Jun YJ, Seo BC. Usefulness of vascularized galeal frontalis myofascial flap as treatment for postoperative infection in frontal sinus fracture. J Craniofac Surg 2011; 22(5):1968-1671.

24. Noury M, Dunn RM, Lalikos JF, Fudem GM, Rothkopf DM. Frontal sinus repair through a frontalis rhytid approach. Ann Plast Surg 2011; 66(5):457-459.

25. Massarelli O, Gobbi R, Soma D, Raho MT, Tullio A. An aesthetically possible alternative approach for craniomaxillofacial trauma: the "pretrichial incision". Craniomaxillofac Trauma Reconstr 2011; 4(3):161-170.

26. Muderris T, Bercin S, Sevil E, Kiris M. Management of frontal sinus fracture: reconstruction of the sinus with iliac bone graft. J Craniofac Surg 2013; 24(2):e194-e195.

27. Koento T. Current advances in sinus preservation for the management of frontal sinus fractures. Curr Opin Otolaryngol Head Neck Surg 2012; 20(4):274-279.

28. de Melo WM, Colete JZ, Mariano RC, Shinohara EH, Souza FA, Garcia IR Jr. Anterior pericranial flap for frontal sinus duct obliteration: is it a valuable resource? J Craniofac Surg 2013; 24(2):e147-e149.

29. Morais de Melo W, Koogi Sonoda C, Garcia IR Jr. Vascular pericranial graft: a viable resource for frontal sinus obliteration. J Craniofac Surg 2013; 24(1):e5-e7.

30. Bui TG, Bell RB, Dierks EJ. Technological advances in the treatment of facial trauma. Atlas Oral Maxillofac Surg Clin North Am 2012; 20(1):81-94. 


\section{Appendix}

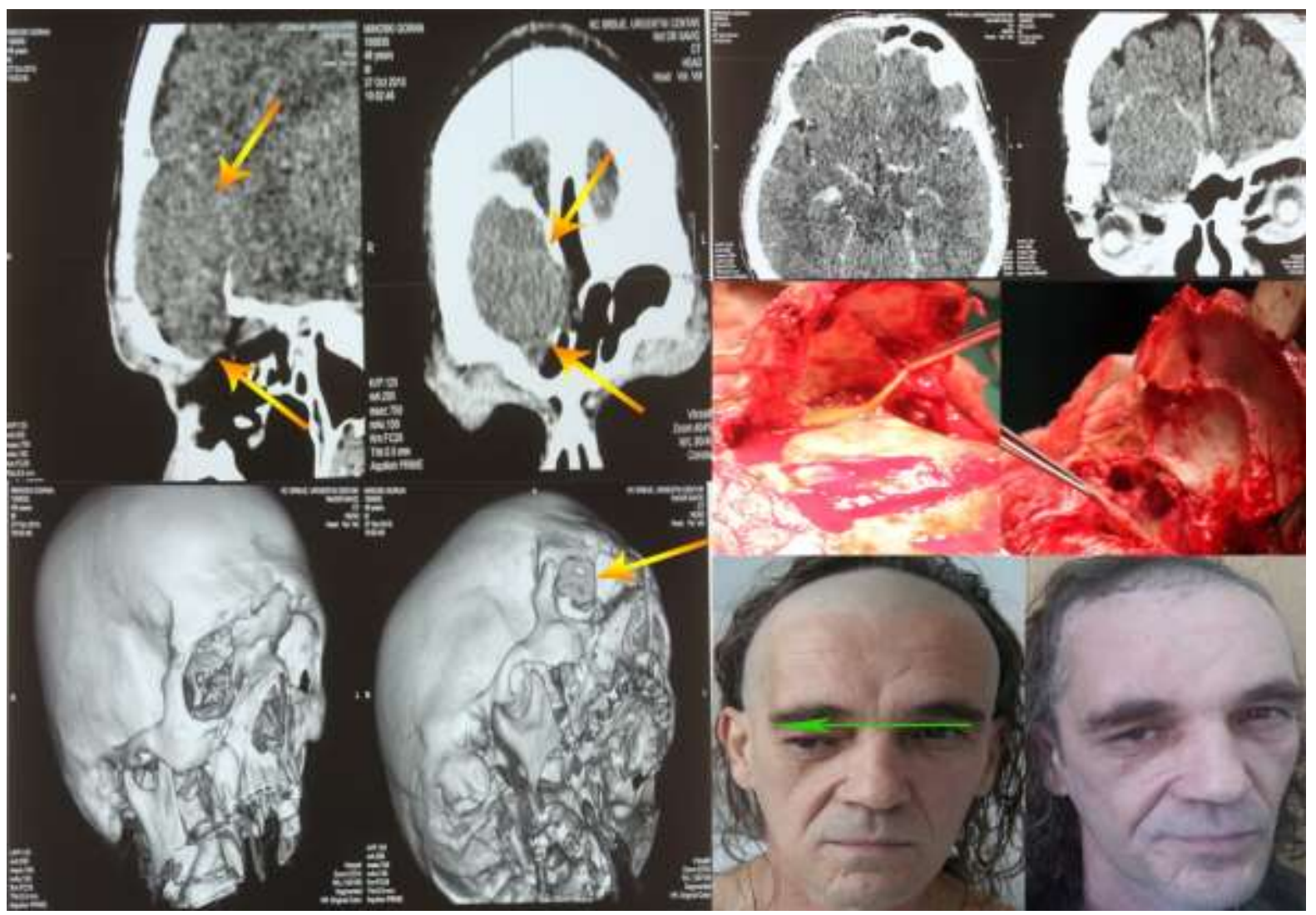

Fig.1 Preoperative evaluation MDCT with 3D reconstruction and operative findings

* Visible proptosis of the right eyelid, eye level below pupillary lines

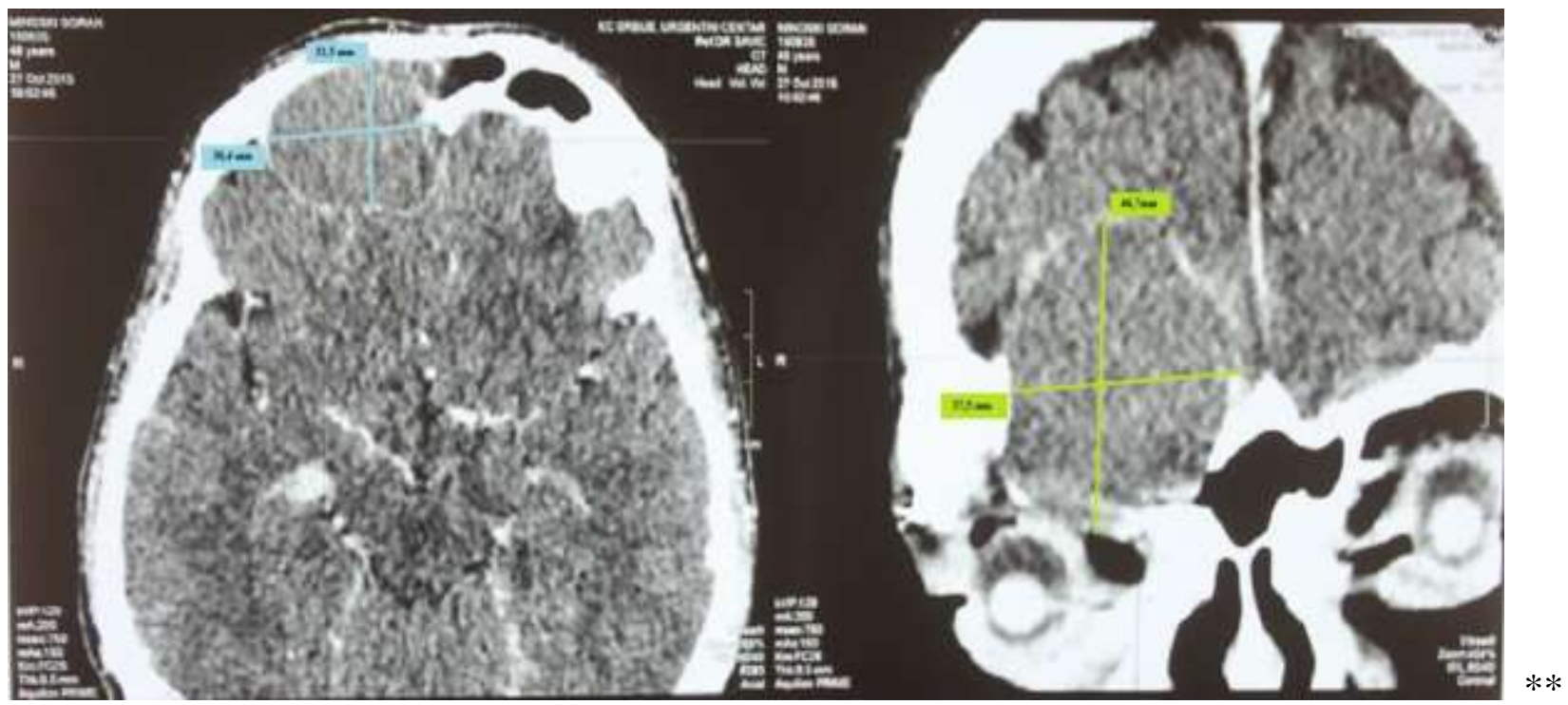

Fig. 2 Diameter of persistent mucocele

Affected right frontal sinus mucocele (HP finding br.1248 / 15: Mucoccela [Prof. Dr. Boričić].

diplopia of the right eye. Horizontal diameter changes $38,4 \times 32,5 \mathrm{~mm}$ and vertical diameter of 37,5 x 46,7mm.

Mucocele with its propagation in orbit fits and suppresses its contents, manifesting proptosis and 


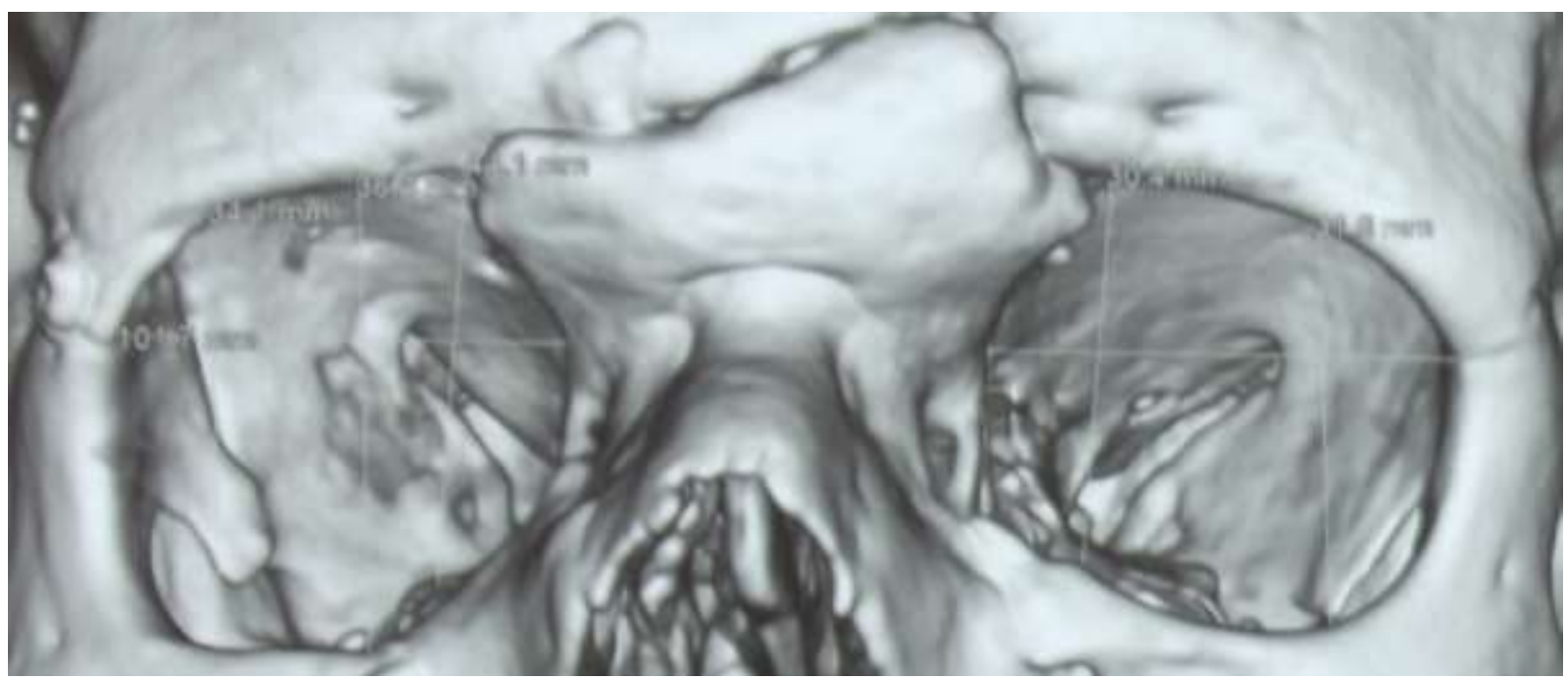

Fig. 3 An impaired diametrical relationship of orbit trauma

${ }^{* * * * *}$ Unrepaired break in the area of the frontal sinus after traffic accidents

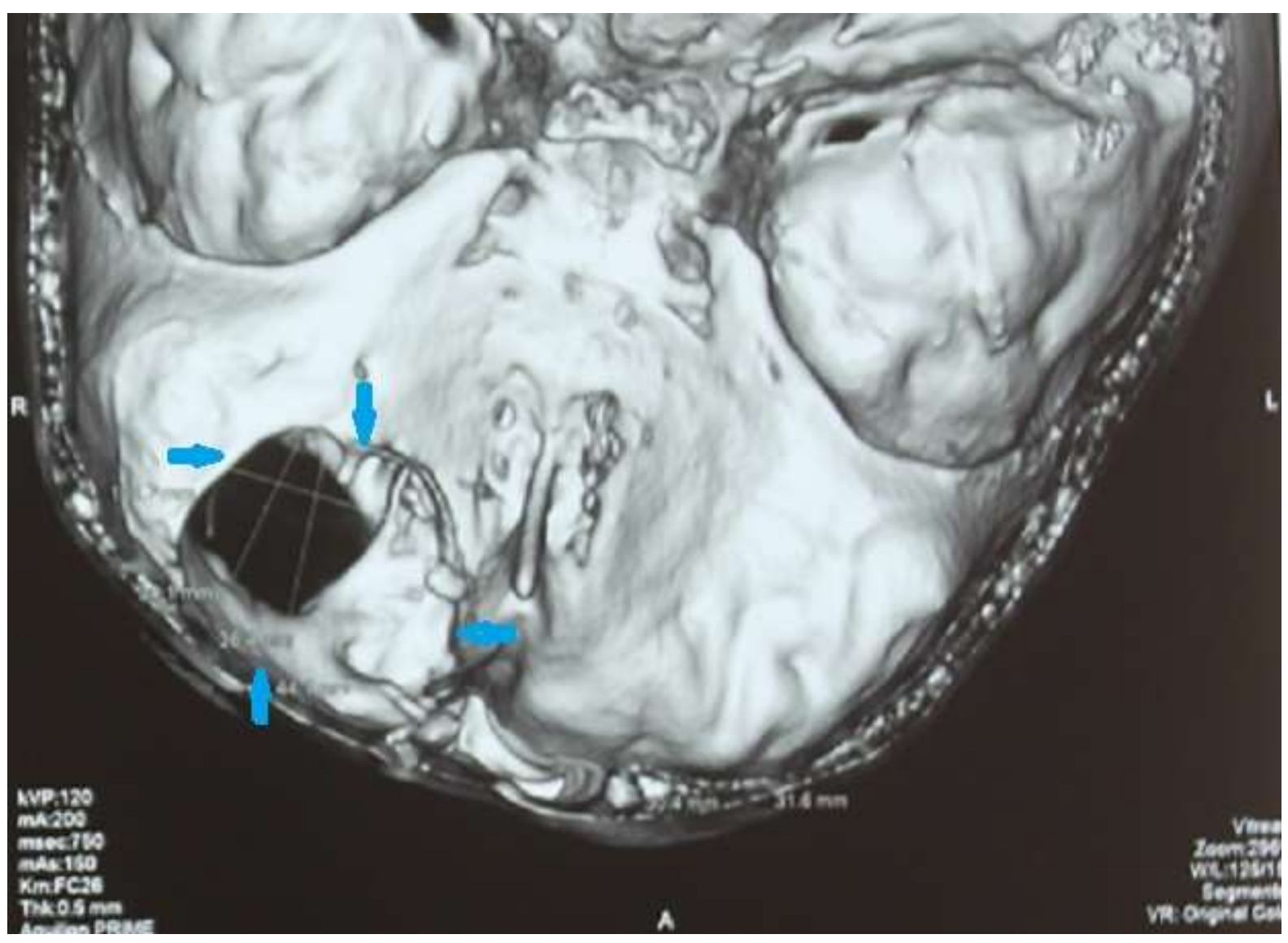

Fig. 4 View of the destruction and its scope on the roof of the right orbit ***** Consideration from the perspective 3D MDCT reconstruction 


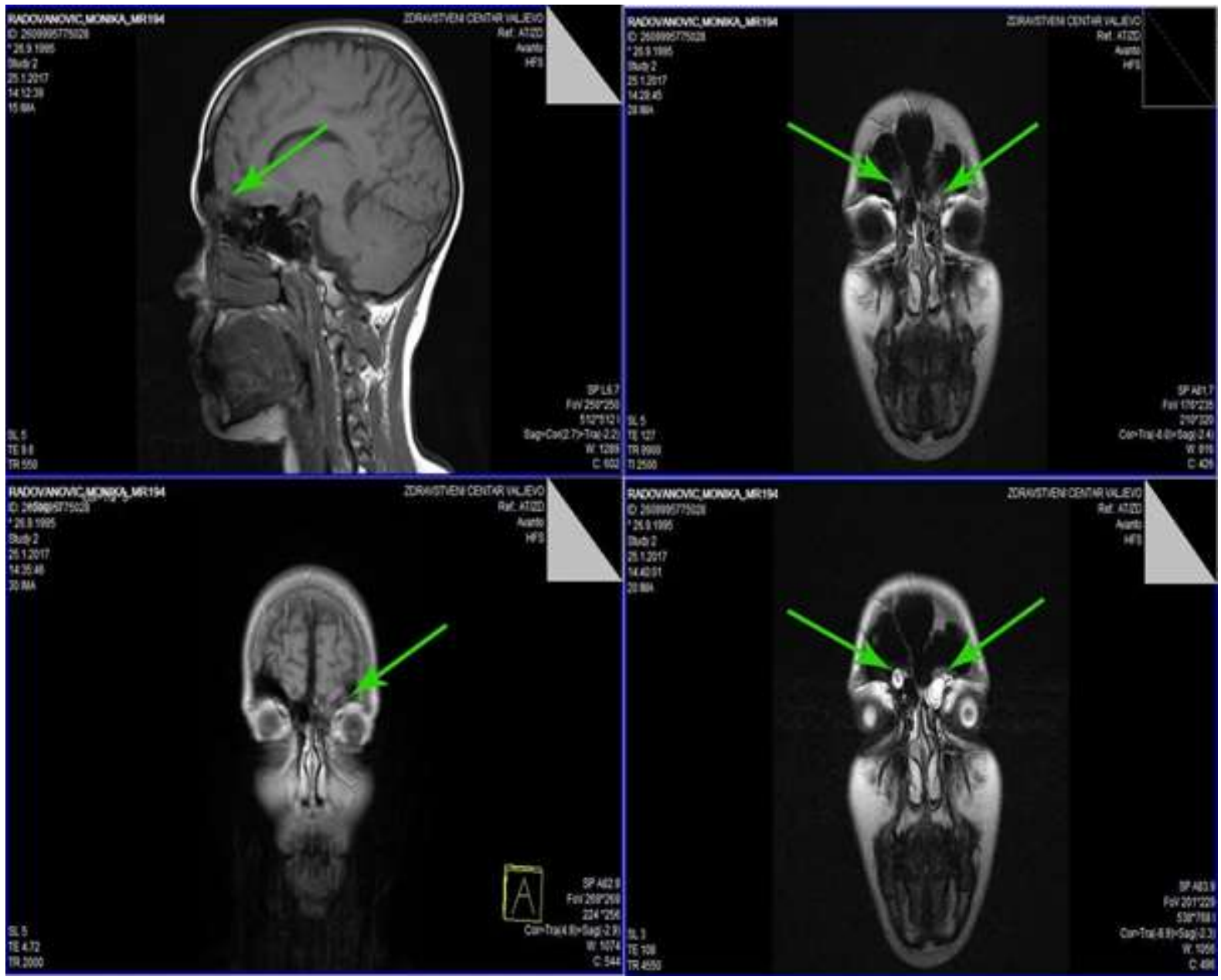

Fig. 5 MR diagnostic display of the patient with two entities of mucocele of the frontal sinuses, with its expansive growth penetrating into the left orbit 